\title{
EFFECT OF POLYMER ON MODIFIED CONCRETE IN RIGID PAVEMENT CONSTRUCTION
}

Shahrukh Khan ${ }^{1}$ and Vinay Deulkar ${ }^{2}$

Abstract: The objective of the study and research is to design polymer modified concrete mix and to trace and analyze the effect of percentage variation of polymer content in concrete mix. The polymer content is varying from $5 \%$ to $25 \%$. The influence of polymer modified concrete results in increase of compressive and flexural strengths of road construction. It is also noted that if polymer content percentage is changed in mix design, it directly affects the required quantity of sand, gravels, water and unit cement content.

Keywords: Polymer modified concrete road, water cement ratio, compressive strength, flexural strength, polymer cement ratio.

\section{INTRODUCTION}

\section{Dissertation Idea:}

Polymer with concrete improves properties such as strength and lower water permeability in comparison to any of the traditional concrete. Polymer is utilized in concrete as an additional mixture to improve resistance to water penetration, durability and improve abrasion resistance. Concrete mix design with polymer is performed. Analysis and comparison of results is done and shown graphically.

Continuously since last several years polymer modified concrete for road construction is tested for its comparative high performance, and sustainability compared to conventional cement concrete. It is also having environmental protection factor.

Polymer emulsion or powder is mixed in fresh concrete mix develops polymer modified concrete for road construction. Polymer modification is used to overcome shortcomings of conventional concrete such as week strength and resistance to corrosion.

\section{Principles of Polymer Modification}

Polymer-based admixtures are used in the form of, polymer latexes, water-soluble polymers and liquid polymers, applied to cementations composites such as concrete. Critical point to be noted is that both polymer film formation polymer film and formation cement hydration proceeds well to yield a monolithic matrix phase with network structure in which the cement hydrate phase and polymer phase interpenetrate. Such polymer-modified concrete structures, possess better properties than traditional cementations composite.

\footnotetext{
${ }^{1}$ Department of Civil Engineering, JIT Borawan, Khargone, MP, India
}

${ }^{2}$ Department of Civil Engineering, JIT Borawan, Khargone, MP, India 
Modification through polymer latex modification is controlled and affected by both cement hydration and polymer film formation. Polymer film formed due to cement hydration process and by the coalescence of polymer particles in polymer latexes. Fact wise both cement hydration and polymer film formation processes form a co-matrix phase. The co-matrix phase is considered as per simplified model given by Ohama.
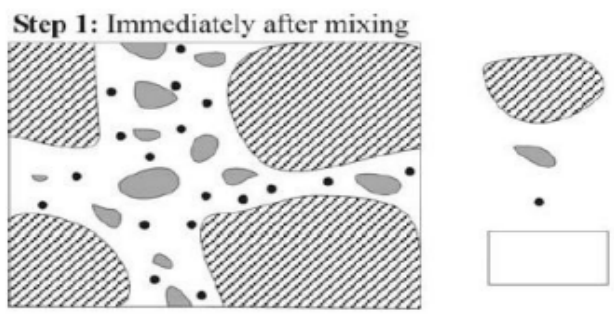

Aggregates
Unhydrated cement particles
Polymer particles
Water

(a) Immediately after mixing

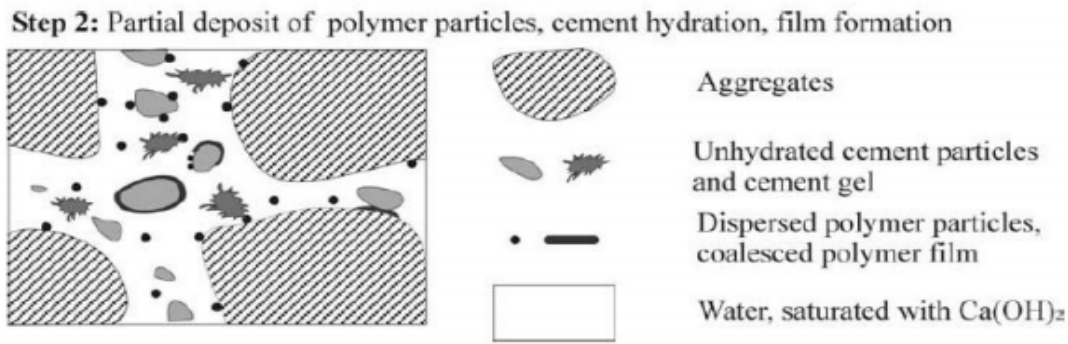

(b) Partial deposit of polymer particles, cement hydration, film formation

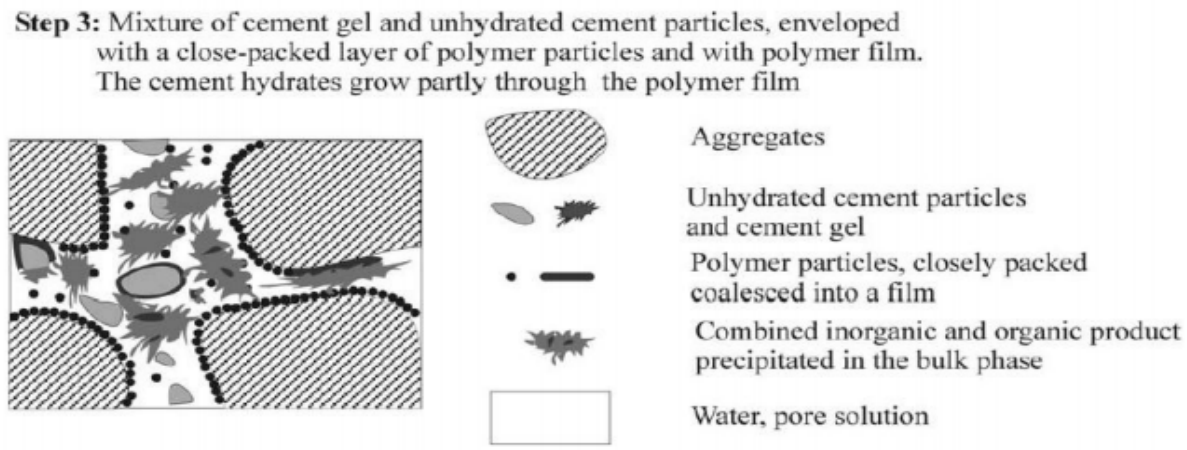

(c) Cement hydration proceeds, polymer film formation starts on specific spots

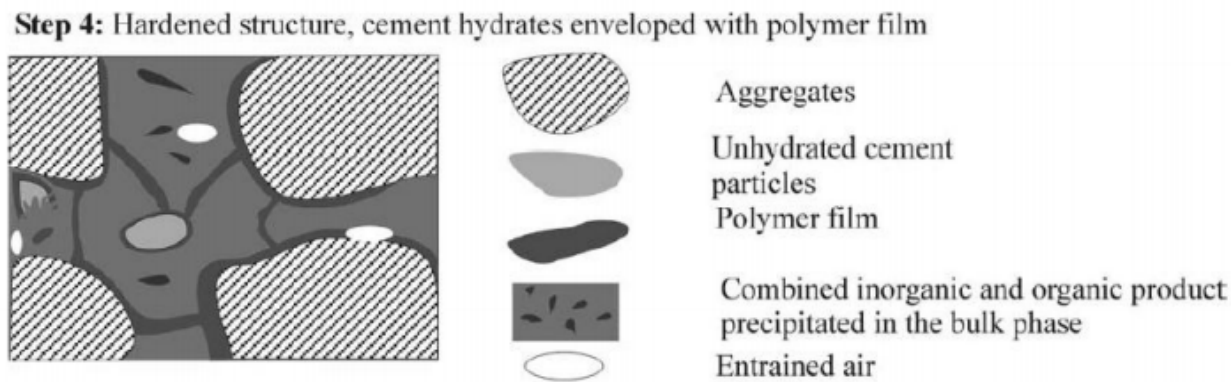

(d) Cement hydration continuous, the polymer particles coalesce into a continuous film

\section{Styrene Butadiene Rubber (SBR) Polymer Modified Concrete}


SBR Polymer is extremely used polymer format in concrete. Figure below presents chemical structure of Styrene butadiene Rubber latexes. Co-polymers of butidine with styrene (styrenebutadine rubber (SBR)), are a group of large-volume synthetic rubbers [8]. Cement hydrates are formed due to adhesion between polymer films. It possess less strain than ordinary concrete and concrete properties also increases i.e. flexural and compressive strength hence, higher durability.

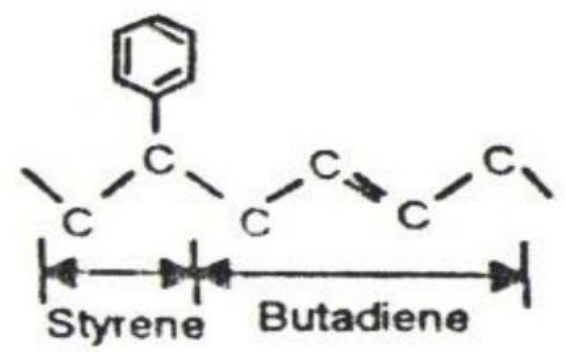

\section{Chemical structures of SBR polymer latexes}

Polymer or monomer are mixed with concrete to modify a mix as polymer modified concrete, curing is performed if necessary. Figure shows application of polymers and monomers to modify cement mix. Latex-modifier are mostly used as a cement modifiers.

Polymers and monomers of any type or class like latexes, water-soluble polymers, liquid resins, and monomets are utilized in concrete and cement composites. Importantly it is required to form cement hydration and polymer phase accurate to achieve or attain monolithic matrix phase in network structure. The properties of polymer modified mix are better than traditional mix due to co-matrix bonding.

Polymers and Monomers for Cement Modificrs

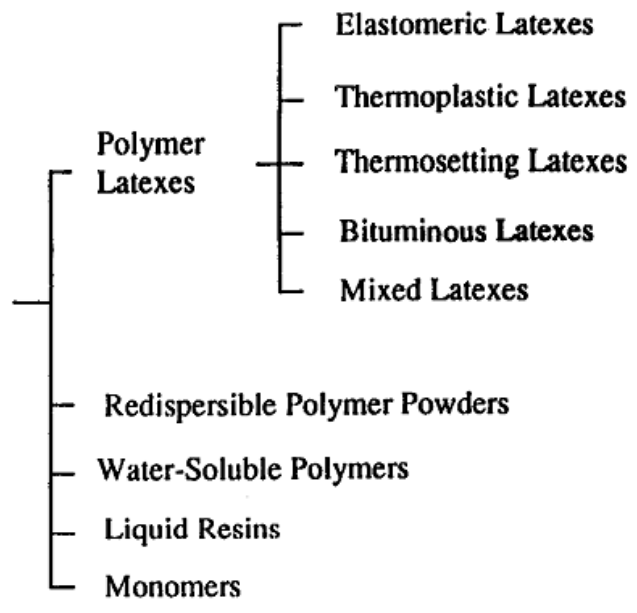

Polymer and Monomers for Cement Modifiers

\section{LITERATURE REVIEW}

Siva Kumar .M.V.N, (2011) This paper presents the effect of different polymers on structural and mechanical properties of concrete. The aim of this study is to investigate the mechanical and 
flexural properties of polymer modified concrete. Two different types of polymers are used at different dosages to modify the cement concrete matrix. Besides, a series of tests without modification was also carried out. By means of four-point loading method, the flexural strength and flexural properties of polymer modified concrete are measured. The influence of different polymers and its optimum dosage in respect of flow and strength characteristics are found. A comparative study has been carried out to highlight the effect of two different polymers on fresh and hardened properties of polymer modified concrete. Based on these results, recommendations are made in respect of its dosage, chemical characteristics and suitability.

S. Thirumurugan, A. Sivakumar, (2013) Synthetic polymer latexes, such as styrene-butadiene rubber (SBR) latex addition in Portland cement has gained wider acceptance in many applications in the construction industry. Polymer-modified cementitious systems seals the pores and micro cracks developed during hardening of the cement matrix, by dispersing a fi $1 \mathrm{~m}$ of polymer phase throughout the concrete. A comprehensive set of experimental test were conducted for studying the compressive properties of SBR latex polymer with crimped polypropylene fibres at relative volume fractions of 0.1 and $0.3 \%$. The results indicated that the addition of polypropylene fibre has little effect on the reduction in the workability of concrete composite containing fly ash and SBR Latex. Increase in polypropylene fibres upto $0.3 \% \mathrm{Vf}$ showed increase in compressive strength upto 57.5MPa. The SBR concrete without fibre showed an increase in strength upto $20 \%$ compared to plain concrete. Test results also indicated that the compressive strength was increased in SBR fibre concrete by means of an ordinary dry curing process than wet curing because of their excellent water retention due to polymer fi $1 \mathrm{~m}$ formation around the cement grains. On the contrary the compressive strength reduces for SBR fibre concretes under wet curing compared to dry curing.

Dr. Bayan S et.al, (2009) This research include the study of Structural Behaviour of Polymer Modified Reinforced Concrete Beams with Styrene Butadiene Rubber (SBR) polymer. Two series of concrete mixtures were used; the first was with moderate compressive strength (level I) and the other with compressive strength higher than the former (level II). Two reference mixes were made also for comparative purposes. This study includes compressive and flexural tests for concrete which was used in this research. The results prove that, polymer modified concrete has compressive and flexural strengths more than reference mixes. Eight beams are moulded of $(95 X 200 X 1600 \mathrm{~mm})$ dimension with different steel reinforcement ratio $(\rho)$. Load-deflection relationships of beams made of polymer modified concretes and references concretes were established. The moment at mid-span with deflection and moment-curvature relationships were established too. The effects of steel reinforcement ratio $(\rho)$ and ( $\rho$ lpmax) on the displacement ductility of reinforced concrete beams were concluded. The PMC beams have a stiffer response in terms of structural behaviour, more ductility and lower cracking deflection than those made by reference concretes and that refer to good role of styrene Butadiene Rubber (SBR) polymer on the properties and behaviour of reinforced concrete beams.

V.M. Sounthararajan et.al, (2013) Steel fibre addition in concrete possesses high merits in terms of achieving homogeneity and tensile strength properties. Polymeric addition in concrete has high advantages in terms of pore filling effect and subsequent increase in durability index. The combined addition of steel and polymeric latex additions in concrete leads to increased strength, durability, toughness, resistance to cracking and crack propagation. Studies were 
conducted in the present study to analyse the properties of concrete that can be further improved with the addition of polymer styrene butadiene rubber emulsion (SBR) along with steel fibres. In this research analysis, styrene-butadiene rubber (SBR) latex as a polymeric admixture was used in steel fibre reinforced concrete. The effect of curing conditions on the strength gain properties of composite steel fibre latex matrix on the compressive, flexural strength, and split tensile test of polymer modified steel fibre reinforced concrete (PSFC) concrete was examined. Including SBR latex at a certain \% of binder in the PSFC concrete improves the bonds within the cement matrix and steel fibres (SF). This is due to the SBR films formed in the matrix. By the comparison of properties of SFC and PSFC, it can be shown that a tremendous increase in compressive strength when $4 \%$ and $8 \%$ SBR is added along with $0.75 \%$ and $1.5 \% \mathrm{SF}$. The increase in flexural strength was noticed and post cracking ductility is imparted to concrete.

L.K. Aggarwal *, P.C. Thapliyal, S.R. Karade, (2007) Water based polymer systems are often used for improvement in the properties of plain cement mortar or concrete. Presently, latexes of a single or combinations of polymers like polyvinyl acetate, copolymers of vinyl acetate-ethylene, styrene-butadiene, styrene-acrylic, and acrylic and styrene butadiene rubber emulsions are generally used. One of the limitations of these polymer systems is that they may re-emulsify in humid alkaline conditions. To overcome this problem, an epoxy emulsion based polymer system has been developed. In this paper the properties of the cement mortar modified with this newly developed epoxy emulsion are compared with those of the acrylic-modified mortar. The results showed that the mortars with the newly developed system have superior strength properties and better resistance to the penetration of chloride ions and carbon dioxide.

F.A. Shaker et.al, (1997) The durability of reinforced concrete structures represents a major concern to many investigators. The use of latex modified concrete (LMC) in construction has urged researchers to review and investigate its different properties. This study is part of a comprehensive investigation carried on the use of polymers in concrete. The main objective of this study to investigate and evaluate the main durability aspects of Styrene-Butadiene latex modified concrete (LMC) compared to those of conventional concrete. Also, the main microstructural characteristics of LMC were studied using a Scanning Electron Microscope (SEM). The SEM investigation of the LMC showed major differences in its microstructure compared to that of the conventional concrete. The LMC proved to be superior in its durability compared to the durability of conventional concrete especially its water tightness (measured by water penetration, absorption, and sorptivity tests), abrasion, corrosion, and sulphate resistance.

\section{PROPOSED METHODOLOGY}

\section{PROBLEM FORMULATION}

Quantities of materials is first to be design and calculated for SBR latex polymer modified concrete. Cement uses is of ordinary Portland cement type with specific gravity 3.17, aggregate river sand of size up to 2.5 with specific gravity 2.62 and river gravel of size 5 to $20 \mathrm{~mm}$ with specify gravity 2.55 , Cement modifier SBR latex with total solids, $47.8 \%$ and specific gravity of polymer is 1.01 , Required slump is taken as $15 \mathrm{~cm}$.

Also problem includes to find out compressive and flexural strength with variation of polymer content in road concrete mix and all other contents like Portland cement and reinforced steel are kept constant for analyse the strength of polymer modified road concrete. 
GRAPHYCALLY CALCULATION

The calculations are performed for design of polymer mix road concrete contents. The procedure and followed as per Handbook Of Polymer-Modified Concrete and Mortars Properties and Process Technology by Yoshihiko Ohama.

EXPERIMENTAL ANALYSIS

Experiment study is carried out and polymer Percentage is varied form $5 \%$ to $25 \%$ and compressive and flexure strength is observed.

- Dimension of cubic structure is taken $150 \times 150 \times 150 \mathrm{~mm}$ for compressive strength.

- Dimension of Prism structure is taken $150 \mathrm{~mm} \times 150 \mathrm{~mm} \times 450 \mathrm{~mm}$ for flexure strength.

- $\quad$ After 28 days of curing Specimen is tested for both and area under curve is measured.

\section{EXPECTED OUTCOMES}

\section{Polymer mix road design conclusion:}

1. Requirement of Ordinary Portland Cement Mix percentage by Volume of the SBR Modified with different percentage of polymer.

2. $\quad$ Suitable SBR Latex Mix percentage by Volume of the SBR Modified Concrete.

3. Requirement of Water Mix percentage by Volume of the SBR Modified with deferent percentage of polymer.

4. Requirement river Sand Mix percentage by Volume of the SBR Modified Concrete with different percentage of polymer.

5. Requirement River Gravel Mix percentage by Volume of the SBR Modified Concrete with different percentage of polymer.

Compressive and Flexural strength comparison conclusion:

6. Compressive Strength with Polymer Mix Percentage.

7. $\quad$ Flexural Strength with Polymer Mix Percentage.

8. Determination of Optimum point at which compressive and flexural strength would be maximum at various polymer mix percentage.

\section{REFERENCES}

[1]. Handbook Of Polymer-Modified Concrete And Mortars Properties and Process Technology by Yoshihiko Ohama.

[2]. Sivakumar .M.V.N, (2011) "Effect of Polymer modification on mechanical and structural properties of concrete - An experimental investigation”, International Journal of Civil And Structural Engineering Volume 1, No 4, 2011, ISSN 0976 - 4399.

[3]. Sagar Sahu, Dr. S. P. Mishra, (2014), "Effect of Polymers in Fresh and Hardened State Of Cement Concrete," International Journal of Innovative Research in Engineering and Technology,Vol. 3, Issue 8, August 2014, ISSN: 2319-8753

[4]. M.A. Islam, M.M. Rahman and M. Ahmed, "Polymer-modified Concrete: World Experience and Potential for Bangladesh," The Indian Concrete Journal, Jan 2011. 
[5]. S. K. Hirde, Omprakash S. Dudhal, "Review on Polymer Modified Concrete And Its Application To Concrete Structures", International Journal of Engineering Research, Volume No.5 Issue: Special 3, pp: 766-769, ISSN: 2319-6890), 2347-5013.

[6]. Kaushal Kishore, IIT roorkee Polymer-Modified Mortars And Concrete Mix Design, http://www.engineeringcivil.com/polymer-modified-mortars-andconcrete-mix-design.html.

[7]. S.S. Verma, "Roads from plastic waste", The Indian Concrete Journal, November 2008.

[8]. IS: 516 - 1959, Indian Standard Methods Of Tests For Strength oF Concrete, June 2006.

[9]. IS: 1204 - 1978, Indian Standard Methods For Testing Tar And Bituminous Materials.

[10]. IS: 2366 (Part IV) - 1963, Indian Standard Methods of Test for Aggregates for Concrete.

[11]. Afroz Sultana.SK, K.S.B. Prasad, "Utilization of Waste Plastic as a Strength Modifier in Surface Course of Flexible and Rigid Pavements", International Journal of Engineering Research and Applications (IJERA) ISSN: 2248-9622, Vol. 2, Issue 4, July-August 2012, pp.1185-1191 